sterilisation there is a risk of infection. Diabetics commonly keep their syringes in spirit although similar practices have been abandoned in hospital, where sterile instruments are now stored dry. It would seem logical for diabetics to store their syringes-glass or plastic-in the same way. Thirty patients reported by Greenough et $a^{3}$ used a single plastic syringe, stored dry in a domestic refrigerator, for up to two months without infection. Nevertheless, using a new needle, as these patients did, does not eliminate the risk of infection since the syringe nozzle may become infected when an infected needle is removed. ${ }^{4}$ The ideal solution would be for diabetics to use a new sterilised syringe and needle for each injection. But the bacteriological risk is clearly small and is not the only consideration. It must be balanced against the cost of meeting it.

${ }^{1}$ Inman PM, Beck A, Brown AE, Stanford JL. Outbreak of injection abscesses due to Mycobacterium abscessus. Arch Dermatol 1969;100: 141-7.

2 Tice PM, Solomon RJ. Disseminated Mycobacterium chelonei infection: response to sulfonamides. Am Rev Respir Dis 1979;120:197-201.

3 Greenough A, Cockcroft PM, Bloom A. Disposable syringes for insulin injection. Br Med f 1979; ;:1467-8.

4 Evans RJ, Spooner ETC. A possible mode of transfer of infection by syringes used for mass inoculation. Br Med f 1950 ;ii :185-8.

(Accepted 14 August 1980)

Department of Clinical Bacteriology and Virology and Unit for Metabolic Medicine, Guy's Hospital, London SE1 9RT

P G JACKSON, MRCP, senior registrar

H KEEN, MD, FRCP, professor

C J NOBLE, MSC, MB, senior registra

N A SIMMONS, FRCPATH, consultant microbiologist

\section{Phenylbutazone overdosage: abnormal metabolism associated with hepatic and renal damage}

Phenylbutazone poisoning is uncommon and apparently has not been reported in the United Kingdom. We report the case of a patient with very abnormal phenylbutazone metabolism in whom hepatic and renal damage occurred.

\section{Case report}

A previously healthy 17-year-old girl was admitted 16 hours after allegedly taking 40 phenylbutazone tablets $(8 \mathrm{~g})$. She did not drink alcohol or take any drugs regularly and the tablets had belonged to her mother. The patient initially fell asleep but woke feeling very unwell with severe nausea. On examination she was drowsy with nystagmus. Intravenous fluids were started because of persistent vomiting. The next morning she developed a sinus tachycardia $(120 / \mathrm{min})$ and was hyperventilating with a respiratory alkalosis (arterial $\mathrm{H}^{+} 32 \mathrm{nmol} / 1\left(\mathrm{pH} \mathrm{7.49)}, \mathrm{PCO}_{2} 2.9 \mathrm{kPa}(22 \mathrm{~mm} \mathrm{Hg})\right.$, and bicarbonate $17 \mathrm{mmol}(\mathrm{mEq}) / \mathrm{l})$. Malaise, drowsiness, and vomiting continued for three days, when jaundice appeared with biochemical evidence of liver damage (figure). The maximum plasma bilirubin concentration, alanine aminotransferase activity, and alkaline phosphatase concentration were $125 \mu \mathrm{mol} / \mathrm{l}$ $(7.4 \mathrm{mg} / 100 \mathrm{ml}), 471 \mathrm{U} / \mathrm{l}$, and $136 \mathrm{U} / 1$ on the $4 \mathrm{th}, 6 \mathrm{th}$, and 8 th days respectively. Tests for hepatitis $B$ surface antigen and antibody were negative and there was no evidence of haemolysis or other haematological toxicity. The plasma albumin concentration remained within normal limits and there was no clinical evidence of fluid retention. Despite adequate fluid replacement there was early but transient impairment of renal function with proteinuria, a reduction in creatinine clearance to $34 \mathrm{ml} / \mathrm{min}$, and a raised plasma urea concentration (figure).

The patient subsequently improved and was discharged on the sixth day, although liver function tests were still abnormal at follow-up nine days later. Serial plasma concentrations of phenylbutazone and its metabolites oxyphenbutazone and $\gamma$-hydroxyphenylbutazone were measured simultaneously by high performance liquid chromatography. ${ }^{1}$ The initial plasma phenylbutazone concentration was grossly raised at $670 \mu \mathrm{g} / \mathrm{ml}$ and the half life, normally about three days, was very short at 23 hours. In contrast to the pattern of metabolites in plasma after therapeutic doses of phenylbutazone ${ }^{2}$ the relative proportions of oxyphenbutazone and $\gamma$-hydroxyphenylbutazone were reversed, with the former disappearing rapidly and high concentrations of the latter, which rapidly exceeded those of the parent drug (figure).

\section{Comment}

The clinical features in this patient resembled those described in the few previous reports of phenylbutazone intoxication, although jaundice does not always occur. Convulsions and gastrointestinal perforation have also been reported. ${ }^{3-5}$ Treatment is of necessity symptomatic. Phenylbutazone is highly bound to plasma proteins and extensively metabolised. ${ }^{2}$ Thus forced alkaline diuresis, dialysis, and haemoperfusion are unlikely to enhance elimination significantly.

Phenylbutazone metabolism was very abnormal in our patient. Despite liver damage the plasma half life was much shorter than
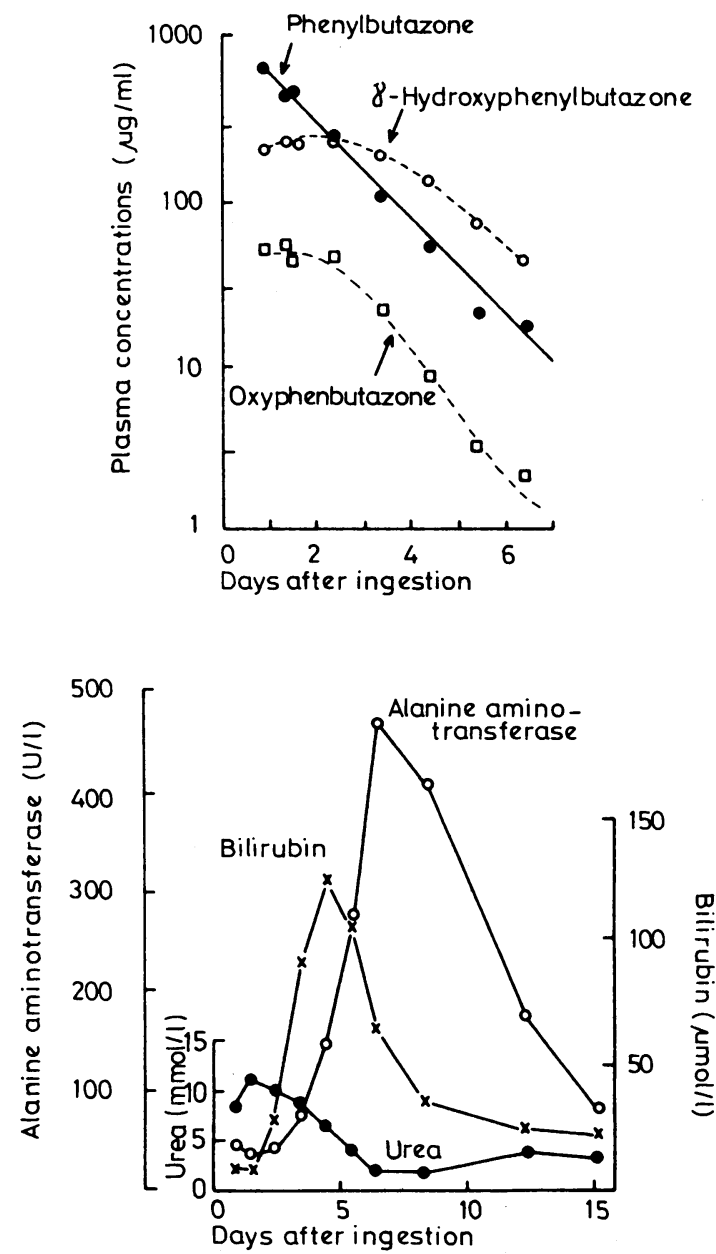

Serial plasma concentrations of phenylbutazone, $\gamma$-hydroxyphenylbutazone, oxyphenbutazone, urea, bilirubin, and alanine aminotransferase after phenylbutazone overdosage.

Conversion: SI to traditional units-plasma bilirubin: 1 $\mu \mathrm{mol} / 1 \approx 0.059 \mathrm{mg} / 100 \mathrm{ml}$. Urea: $1 \mathrm{mmol} / 1 \approx 6 \mathrm{mg} / 100 \mathrm{ml}$.

previously described ${ }^{2}$ and the concentrations of $\gamma$-hydroxyphenylbutazone were extraordinarily high. This metabolite normally accounts for under $5 \%$ of the total drug and metabolites in plasma after a single therapeutic dose of phenylbutazone, although a somewhat higher percentage has been reported after longer-term administration. ${ }^{2}$ In four other cases of minor overdosage of phenylbutazone we found that $\gamma$-hydroxyphenylbutazone, oxyphenbutazone, and phenylbutazone accounted on average for 3\%, 14\%, and $83 \%$ respectively of the total in plasma, and the maximum for $\gamma$-hydroxyphenylbutazone was $6 \%$. Thus in our patient the pattern of metabolites was completely reversed. Possible explanations include greatly increased production of $\gamma$-hydroxyphenylbutazone, concentrationdependent saturation of aromatic hydroxylation, and impaired renal excretion of the $\gamma$-hydroxy metabolite. The kinetics, however, were not consistent with saturation, and increased $\gamma$-hydroxylation seems the most likely cause in view of the unusually short half life of the parent drug. The hepatotoxicity of phenylbutazone may be mediated through metabolic activation (as with paracetamol), and we are tempted to postulate a relationship between abnormal metabolism of the drug in this patient and subsequent liver damage. 
We are indebted to Dr J G Domenet for providing reference samples of phenylbutazone and its metabolites.

${ }^{1}$ Prescott LF, King IS, Brown L, Balali M, Adriaenssens PI. HPLC in clinical pharmacological studies of analgesic drugs. Proceedings of the Analytical Division of the Chemical Society 1979;16:300-2.

2 Aarbakke J. Clinical pharmacokinetics of phenylbutazone. Clin Pharmacokinet $1978 ; 3: 369-80$.

3 Wramner T. A case of poisoning with 10 grams of Butazolidin. Acta Rheum Scand 1957;3:82-91.

4 Juul J. Acute poisoning with Butazolidin (R) (phenylbutazone). Acta Paediatr Scand 1965;54:503-7.

5 Farber D, Liel E. Phenylbutazon-Vergiftung im Kindesalter. Tägliche Praxis 1968;9:231-3.

(Accepted 5 April 1980)

University Department of Therapeutics and Clinical Pharmacology and the Regional Poisoning Treatment Centre, Royal Infirmary, Edinburgh EH3 9YW

L F PRESCOTT, MD, FRCPED, reader and consultant physician

J A J H CRITCHLEY, PHD, MRCP, lecturer

M BALALI-MOOD, MD, research fellow

\section{Hypercalcaemia and osteolytic bone lesions in chronic lymphocytic leukaemia}

Hypercalcaemia and pathological fractures are common in some lymphoproliferative disorders, such as myeloma, but are extremely rare in chronic lymphocytic leukaemia. The patient described here presented with pathological fractures of the right humerus and left femur and was shown to be hypercalcaemic, apparently because of chronic lymphocytic leukaemia. Despite a careful search no other cause for the fractures and disturbance of calcium bone metabolism was found.

\section{Case report}

A 73-year-old Caucasian woman presented to the accident and emergency department with multiple pathological fractures of the right humerus and left hip. No history of major trauma was obtained.

Examination showed pallor, and painless small rubbery lymphadenopathy in the groin, axilla, and neck. The spleen was enlarged four centimetres below the left costal margin. A subcapital fracture dislocation of the left hip and a fracture of the neck and shaft of right femur were also detected. Osteoporotic areas and possible lytic lesions were seen around the fracture sites. The haemoglobin concentration was $9.3 \mathrm{~g} / \mathrm{dl}$ and the white blood cell count $28.0 \times 10^{9} / 1\left(28000 / \mathrm{mm}^{3}\right)$ with $7 \%$ smear cells and $78 \%$ small mature lymphocytes. Biochemical investigations showed a serum calcium concentration of $3.9 \mathrm{mmol} / 1(15.6 \mathrm{mg} / 100 \mathrm{ml})$, serum phosphate concentration of $1.7 \mathrm{mmol} / 1(5.6 \mathrm{mg} / 100 \mathrm{ml})$, serum alkaline phosphatase activity of $15 \mathrm{KA}$ units, and serum albumin concentration of $38 \mathrm{~g} / \mathrm{l}$. Serum parathyroid hormone concentration was $0.25 \mathrm{ng} / \mathrm{ml}$ (normal $<1.0 \mathrm{ng} / \mathrm{ml}$ ).

Examination of a lymph-node biopsy sample taken from the neck showed infiltration with lymphocytic cells. Studies on the lymphocytes showed the presence on the cell surface of both immunoglobulin $M$ and immunoglobulin D. The cells were monoclonal B cells, expressed receptors for mouse erythrocytes, and formed rosettes. Surface marker studies were performed simultaneously on peripheral circulating lymphocytes, which expressed closely similar patterns. These results are diagnostic of chronic lymphocytic leukaemia. ${ }^{1}$

A bone scan (using technetium methylene diphosphonate) displayed areas of high uptake at the fracture sites and also in the ribs and vertebrae. Examination of marrow aspirate showed reduced granulopoiesis and thrombopoiesis plus $93 \%$ mature small lymphocytes-similar to those found in the peripheral circulation.

A left Thomson's hip prosthesis was inserted. The femoral head was removed and sent for histological examination; the tissue removed from the femoral head was identical with that in the lymph-node biopsy sample, and there was no evidence of any other neoplastic cell type. Histological examination of the affected bone showed large numbers of osteoclasts around the tumour cell mass. Treatment of the hypercalcaemia was started with oral phosphate Phosphate-Sandoz; $0.5 \mathrm{~g}$ three times daily) followed by oral 3-amino-1-hydroxypropylidene 1-biphosphate $(370 \mathrm{mg}$ three times daily, then $125 \mathrm{mg}$ three times daily). Hypercalcaemia was reversed by both treatments (figure). Two weeks after surgery the patient was given chlorambucil

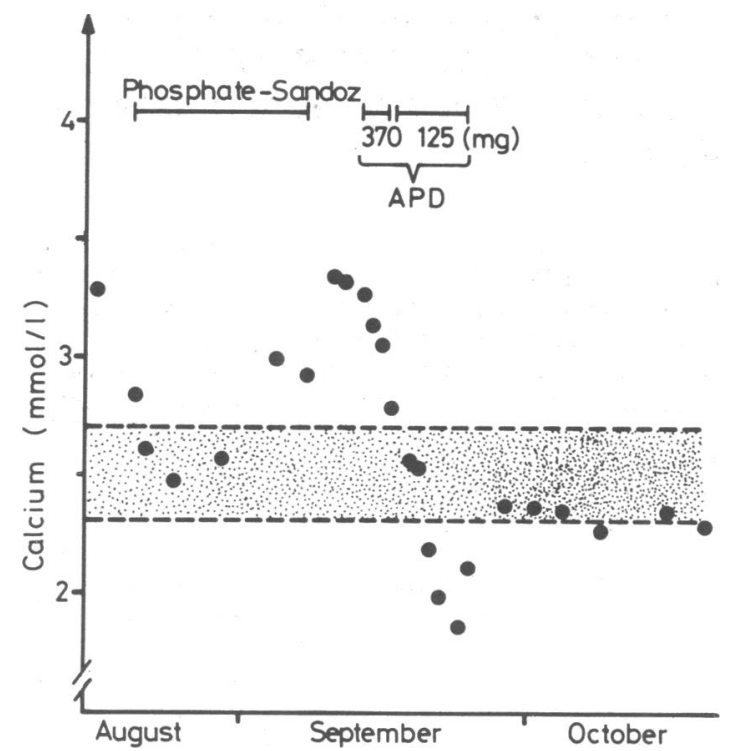

Effects of Phosphate-Sandoz and 3-amino-1-hydroxypropylidene-1-biphosphate (APD) on serum calcium concentration. Shaded area indicates range of normal values.

$5 \mathrm{mg} /$ day for four weeks. With this treatment the abnormal peripheral blood changes were completely reversed. The response in white blood cell count was dramatic. Treatment of hypercalcaemia was accompanied by symptomatic improvement, return of appetite, reduced thirst, and reduced frequency of micturition. The patient remained normocalcaemic for over six weeks without treatment and was able to return home to lead a normal life style.

\section{Comment}

Hypercalcaemia and bony spread in chronic lymphocytic leukaemia is a rare association, and in all reported cases there does not appear to have been histological confirmation of bony spread.

The above changes are well described in myeloma and other lymphoproliferative disorders, but our histology and surface marker studies indicate that this patient had chronic lymphocytic leukaemia. Another feature was the large number of osteoclasts seen around the tumour mass. The appearances lend support to the existence of an osteoclast activating factor released by neoplastic cells of the tumour mass. Release of this factor has been shown in cells of lymphosarcoma type by Mundy et $a l^{2}$ but not before in a patient with chronic lymphocytic leukaemia.

Interestingly, in a similar case Laugen et $a^{3}$ found raised immunoreactive parathyroid hormone concentrations. In our case parathyroid hormone concentrations were normal. In several other reported cases parathyroid hormone concentrations have not been raised except in the presence of renal failure.

We therefore suggest that in this patient the hypercalcaemia was probably due to secretion of osteoclast activating factor by malignant lymphocytes, as the degree of hypercalcaemia seen in this case would be difficult to explain on the basis of fractures and subsequent immobility in an elderly patient with slow bone turnover rate and in the absence of Paget's disease.

1 Anonymous. Cell surface markers in chronic lymphocytic leukaemia. $\mathrm{Br}$ Medf 1979;ii:886-7.

2 Mundy GR, Rick ME, Turcotte R, Kowalski MA. Pathogenesis of hypercalcemia in lymphosarcoma cell leukemia. Am f Med 1978;65:600-6.

${ }^{3}$ Laugen RH, Carey RM, Wills MR, Hess CE. Hypercalcaemia associated with chronic lymphocytic leukemia. Arch Intern Med 1979;139:1307-9.

(Accepted 18 August 1980)

Queen Elizabeth Hospital, Birmingham B15 2TH

P MCMILLAN, MB, BS, senior house officer

G MUNDY, MD, senior research fellow (present appointment: resident physician, University of Texas Health Science Centre, San Antonio, Texas 78284, USA)

Selly Oak Hospital, Birmingham B15 2TH

P MAYER, BM, MRCP, consultant geriatrician 